\title{
Academic Entrepreneurship in a Medical University: A System Dynamics Approach
}

\author{
Sharam Tofighi14, Ehsan Teymourzadeh ${ }^{15}$, Ghader Ghanizadeh ${ }^{16}$
}

\begin{abstract}
Academic entrepreneurship is a dynamic field which is growing after the second academic revolution that added entrepreneurial mission as the Third Mission of universities. In this sense, dynamics of this phenomenon is a suitable field of study and provides fruitful insights for both theory and practice. Thus, in this research, system dynamics approach is used to scrutinize academic entrepreneurship. The main question of this research is "how academic entrepreneurship might evolve in a medical university of a developing country?" Therefore, Cross Impact Analysis method is used to examine the system behavior. In this study, the main attributes are adapted from a recent study by Salamzadeh et al. (2013a). Then, some policy variables are proposed and their effects on the model were shown. Findings show that although entrepreneurial ecosystem is growing in the country, still there are problems to be taken into account in order to improve the entrepreneurship in university.
\end{abstract}

KEY WORDS: Academic Entrepreneurship, System Dynamics Approach, Medical University

JEL: L26,L31,I15

UDC: 005.961:005.914.3]:378

005.344

COBISS.SR-ID 238309900

\footnotetext{
${ }^{14}$ Health Management Research Center, BUMS, Tehran, Iran

${ }^{15}$ Health Management Research Center, BUMS, Tehran, Iran

${ }^{16}$ Health Management Research Center, BUMS, Tehran, Iran
} 


\section{INTRODUCTION}

Entrepreneurship is considered as an influential tool to improve firms, and especially business ventures (Gartner, 1990; Howorth, 2005). However, it entered into academic entities after the second academic evolution in the mission of universities which turned the pages and made universities more effective in their societies (Keast, 1995; Klofsten, 2000). The new mission, which is called the Third Mission, requires universities and academic institutions to be more entrepreneurial, and thus to contribute to socio-economic development of the country and the region into a greater extent (Etzkowitz, 2003). It should be noted that education and research are respectively the first and the second missions of universities and indeed these two are considered in an entrepreneurial university (Etzkowitz, Leydesdorff 2000; Laredo, 2007; Jongbloed et al., 2008).

As Kirby (2006) argues, universities are considered as important catalysts for international, national and regional economic and social development as those entities develop productive and creative links between education and research. Therefore, any top university or academic institution may focus on the Third Mission to be able to compete with others and to handle the needs and challenges faced in their communities and societies. Although, it should be taken into account that as some scholars such as Sooreh et al. (2011) mention, academic entrepreneurship and the philosophy of entrepreneurial universities goes far beyond mere engagement with industries (e.g. Acworth, 2008; Perkmann, Walsh, 2009; Bruneel, et al. 2010). Topics such as spin off creation process (Chrisman et al., 1995), university Technology Transfer (UTT) (Dill, 1995), new venture creation (Salamzadeh, 2015), commercialization of university research (Tanha et al., 2011), academic status (Guerrero et al. 2014), startup companies (Salamzadeh, Kawamorita Kesim, 2015, 2017) and the like are included in the literature of academic entrepreneurship.

The topic was controversial until Etzkowitz (2003) introduced the concept of "Triple Helix" that elaborates the way universities and academic institutions contribute in innovative and entrepreneurial activities of their regions. This concept deals with the relationship between "university-industry-government" and determines how these entities interact with each other to promote the innovation cycle. After introducing this ideas (Etzkowitz, 1998, 2003), other scholars started studying the dynamics in a variety of contexts (e.g. see, Etzkowitz et al. 2000; Etzkowitz and Leydesdorff, 2000; Etzkowitz, 2001, 2002, 2003; Etzkowitz and Brisolla, 2002; Etzkowitz and Zhou, 2008; Lu and Etzkowitz, 2008; Etzkowitz, 2011 a,b; Svensson et al. 2012).

Yet, entrepreneurial universities and academic entrepreneurship was rarely examined and studied in developing countries. Although there are some research papers which discussed the status in different countries. For instance, Dana (2001) investigates Asian countries including India, Indonesia, Malaysia, the Philippines, and Singapore, Etzkowitz and Mello (2004) discussed the topic in Brazil, and Salamzadeh et al. (2013a) studied it in Iran. As Mian (2006) and Etzkowitz and Mello (2004) believe entrepreneurial universities and academic entrepreneurship in developing countries are more at a normative level. Then, as prior research shows, entrepreneurial universities and academic entrepreneurship are in their embryonic stage. In our case, in Iran, the literature on entrepreneurial universities and academic entrepreneurship is somehow limited (see, Salamzadeh, 2011; Sooreh et al, 2011; Farsi et al, 2012; Guerrero et al, 2015; Salamzadeh et al., 2013a; Guerrero et al., 2014); while such efforts were started two decades ago in European and north American countries.

Moreover, academic entrepreneurship is more important in medical sciences which directly contribute to socioeconomic development of the regions and the countries. Therefore, the main questions of this research are: "how academic entrepreneurship might evolve in a medical university of a developing country?", and "how different policy variables influence this transition from a second generation to a third generation university?" In this paper, the authors 
examine the issue in question through studying the existing dynamics between four main entities, i.e. (i) resources, (ii) capabilities, (iii) mission, and (iv) impeding factors (see Salamzadeh, 2013a). Then, some policy variables are entered into the model in order to examine the system behavior.

\section{ACADEMIC ENTREPRENEURSHIP IN MEDICAL UNIVERSITIES}

The literature on entrepreneurial universities has rarely paid attention to medical universities. However, there are footprints of such movements in medical technologies, such as bioscience (Kemp et al., 2012; Andersson \& Berggren, 2016). Albeit, some scholars believe that talking of entrepreneurial movements has nothing to do with medical staff (e.g. Gibb \& Hannon, 2006), to some others medical staff, and more precisely, doctors could be considered as entrepreneurs (Stone, 1997; Mautner, 2005; Khanna, 2016). Therefore, based on the second perspective, universities must become more and more entrepreneurial to succeed in training such individuals (e.g. see Loxley \& Seery, 2012); otherwise, this could only turn into a myth. Moreover, "health care reform poses a set of challenges for research universities with large medical centers", as mentioned by Thorp \& Goldstein (2013). For all these reason, these entities must be more willing to join the entrepreneurial movement (De-liang, 2012). It is noteworthy that the idea of investigating academic entrepreneurship in medical universities is in its embryonic stages, and it will draw the attention of medical officials sooner or later.

\section{THE MODEL}

In 1960s, Theodore Gordon and Olaf Helmer developed Cross Impact Analysis (CIA) method/technique in order to solve the forecasting problems (Pedamallu et al. 2011). This method is among the most well known methods in system thinking approaches, which is developed in order to identify and examine the relationships between system variables/entities. This method is rarely used in entrepreneurship research and mostly used in solving nonentrepreneurial problems (e.g. Pedamallu et al. 2011, Hayashi et al. 2006), until in 2013a, Salamzadeh et al. (2013a) took advantage of it to study entrepreneurial universities. Moroever, this version which is used in this paper is a non-probability version of CIA which was only used by Salamzadeh et al. (2013a) in entrepreneurship research. A model is designed based on the mentioned study, and tailored with CIA requirements. In the next sections of the paper, the methodological sequence offered by CIA method determined the structure of the paper. Figure 1 shows the steps of the CIA method through a diagram. 


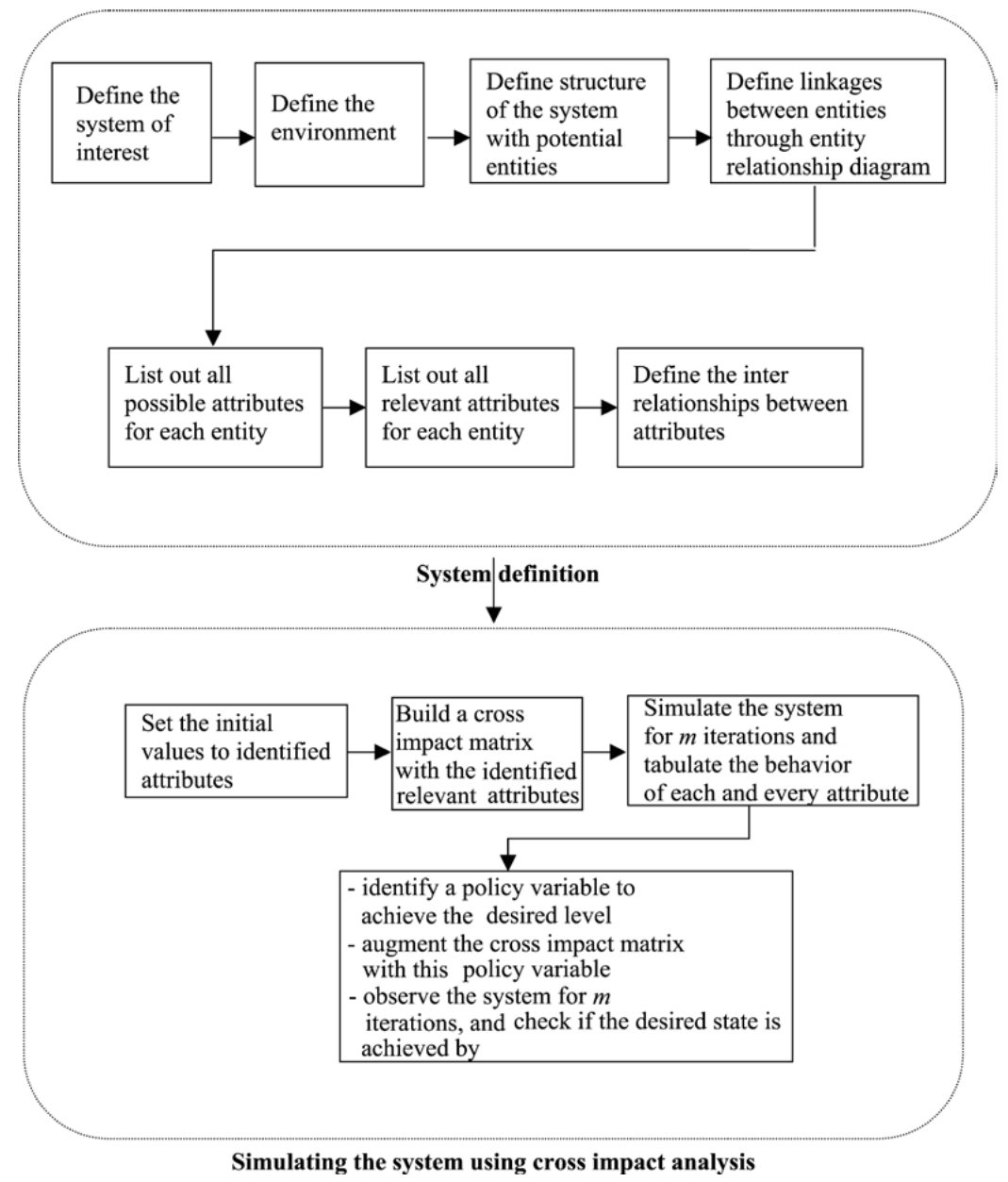

Figure 1. Block diagram for the steps of the CIA method

Source: (Pedamallu et al., 2011)

\section{DEFINING THE SYSTEM}

As mentioned earlier, a typical system dynamics model shows the interaction of a set of entities which produces a set of outputs. In such a model, the entities are defined in a way that enables the problem solver to conceptualize the problem in order to solve it. The system behavior is a result of interactions between the entities. Here, Salamzadeh et al.'s (2013a) perception of the problem is used to conceptualize the model. To elaborate the model, the following issues should be discussed:

(i) Environment

(ii) Structure: Here, system structure entails the following entities:

1. Mission,

2. Impeding factors,

3. Resources, and

4. Capabilities. 
The entities are defined based on Farsi et al.'s (2012) conceptualization of entrepreneurial universities in Iran, and Guerrero et al.'s $(2006,2014)$ study of entrepreneurial universities in Spain and Iran. Resource based view (RBV) is the basic theory behind these entities- i.e. the internal factors have been grouped into resources and capabilities supported by the RBV. As a complementary theoretical framework, the RBV helps to explain the internal factors- resources and capabilities- that generate a competitive advantage in the context of an entrepreneurial university (Guerrero and Urbano, 2010). It should be noted that the entities are used in other studies as well (e.g. see, Guerrero and Urbano, 2010; Guerrero et al., 2011; Salamzadeh et al., 2013a).

(iii) Linkages: Linkages among the entities in a dynamic model could be in different styles, such as physical, electro-magnetic, and information based linkages (Pedamallu et al., 2011). In this study, Salamzadeh et al.'s (2013a) approach is followed to define the type of relationships among the entities (Figure 2). Thus, three types of relationships are proposed: Navigation relationship $\left(\mathrm{R}_{1}\right)$; Impeding relationship $\left(\mathrm{R}_{2}\right)$; Synergizing relationship $\left(\mathrm{R}_{3}\right)$.

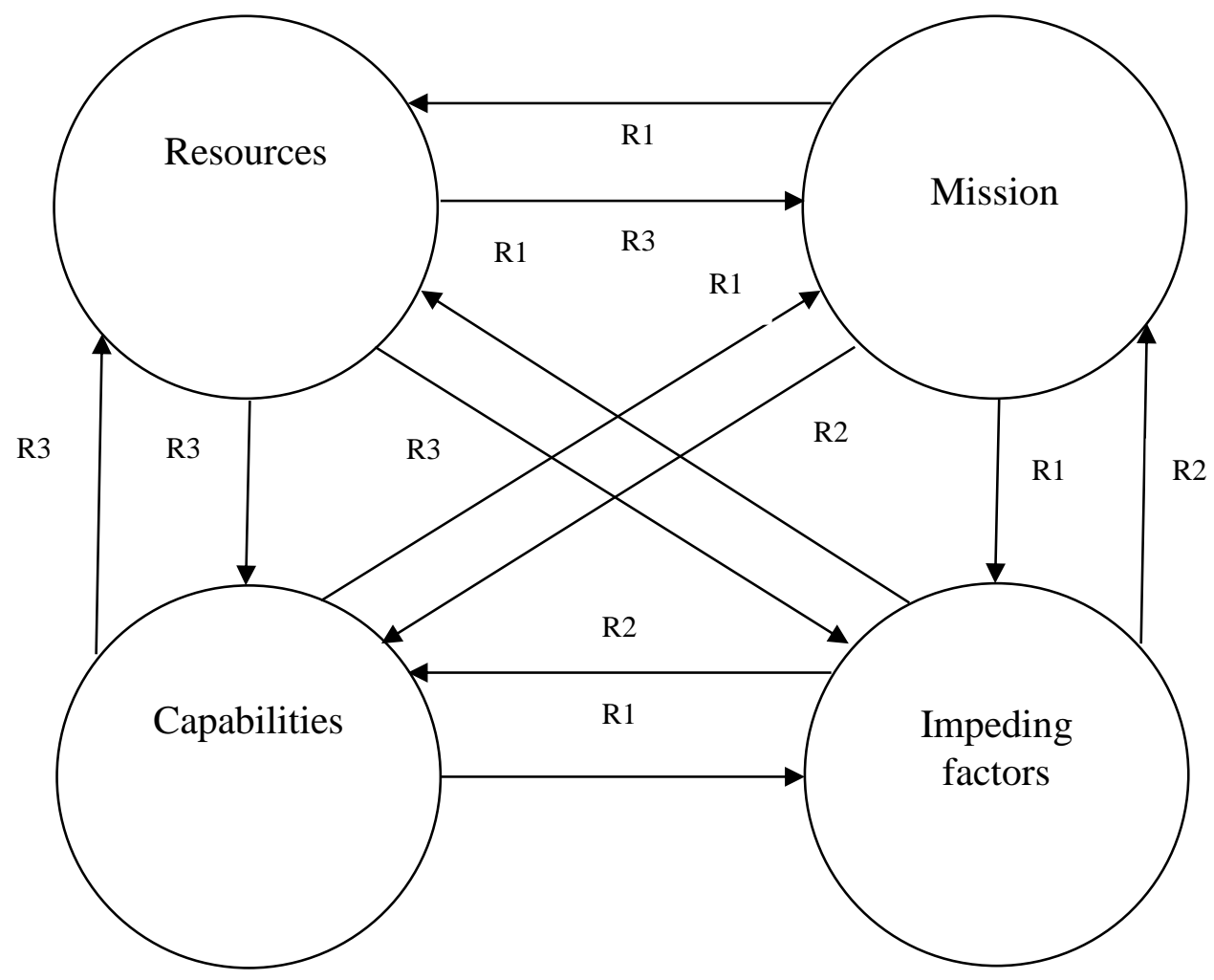

Figure 2: Entity relationship diagram

\section{System entities and relationships equations}

As Pedamallu et al. (2011) argue, in system dynamics approach "the dynamic change of the system state is referred to as system behavior. The state of a system is an instantaneous snapshot of levels (or, amounts) of the relevant attributes (or, characteristics) possessed by the entities that constitute the system". Each entity includes a series of attributes which affect the system in long or short terms. To define the system appropriately, the person in charge of defining it should carefully determine the attributes. As mentioned earlier, the attributes are defined based on prior research (see Salamzadeh et al., 2013a). Table 1 shows the entities and attributes of the model. It should be noted that several entrepreneurial university models are 
available in the literature, among which the authors studied those which used a Resource Based View (RBV) towards studying this phenomenon (e.g. see Guerrero et al., 2006, 2011, 2015; Kirby et al., 2011; Sooreh et al., 2011; Salamzadeh et al., 2011, 2015; Guerrero and Urbano, 2014; Urbano and Guerrero, 2013; Farsi et al., 2014).

Table 1: Entities and attributes of the model

\begin{tabular}{||l|l|}
\hline Entity & \\
\hline Mission & Generating Entrepreneurs \\
\hline \multirow{4}{*}{ Resources } & Applied research \\
\cline { 2 - 2 } & Knowledge and technology transfer \\
\cline { 2 - 2 } & Contribution in socio-economic development \\
\cline { 2 - 2 } & Developing an entrepreneurial culture \\
\cline { 2 - 2 } & Hard resources \\
\hline \multirow{4}{*}{ Capabilities } & Soft resources \\
\cline { 2 - 2 } & Status and localization \\
\cline { 2 - 2 } & Background \\
\cline { 2 - 2 } & Networks and partners \\
\cline { 2 - 2 } Impeding factors & Resource absorption and management \\
\cline { 2 - 2 } & Political behavior and lobbying \\
\cline { 2 - 2 } & Resistance \\
\hline
\end{tabular}

Source: (Salamzadeh et al., 2013a)

The interaction between entities is determined based on the relationships of the attributes. As these attributes change, the system behavior changes in a certain direction. The interactions affect the system behavior in two ways, either desirable or undesirable. In fact, attributes are variables of the model which might be controlled directly or indirectly. Also, policy variables might affect system behavior. Introducing policies and measure those policies through considering policy variables could lead to a better understanding of and analyzing the system behavior. However, in system dynamic approach some presumptions should be taken into account (e.g. see, Kane 2002; Pedamallu et al., 2011). Keeping those in mind, the following mathematical structure is considered in this study.

(1) $0<x_{i}(t)<1$, for all $i=1,2, \ldots, N$, and all $t \geq 0$

Where $x_{i}(t)$ is the level of attribute $i$ in period $t$. A transformation is used to calculate $\mathrm{x}_{\mathrm{i}}(\mathrm{t}+\Delta \mathrm{t})$, in order to preserve boundedness.

(2) $x_{i}(t+\Delta t)=x_{i}(t)^{P}$

Where the exponent $\mathrm{P}_{\mathrm{i}}(\mathrm{t})$ is calculated as

$$
P_{i}(t)=\frac{1+\frac{\Delta t}{2} \sum_{j=1}^{N}\left(\left|\alpha_{i j}\right|-\alpha_{i j}\right) x_{j}}{1+\frac{\Delta t}{2} \sum_{j=1}^{N}\left(\left|\alpha_{i j}\right|+\alpha_{i j}\right) x_{j}}
$$

(3) Where $a_{i j}$ are the elements of the CIA matrix, which show the impact of attribute $x_{j}$ on $x_{i}$, and $\Delta t$ is the period of each iteration in simulation. Equation 3 guarantees that $P_{i}(t)>0$ for all $\mathrm{i}=1,2, \ldots, \mathrm{N}$, and all $\mathrm{t}>0$. Equation 2 is also preserves the boundedness condition. Moreover, equation 3 could be shown as follows:

$$
P_{i}(t)=\frac{1+\Delta t \mid \text { sumof negativeimpacts on } x_{i} \mid}{1+\Delta t \mid \text { sumof pos itiveimpacts on } x_{i} \mid}
$$




\section{Simulating the system using cross impact analysis}

In this stage, the system is completely defined and prepared for simulation. In this case, four steps in two phases are considered to run cross impact analysis. First, the simulation model is run as it is, and without entering any intervening factors (policy variables). Second, the simulation is repeated entering some policy variables to study the changes in system behavior (see Pedamallu et al, 2011; Salamzadeh et al., 2013a).

Step 1. Set the initial values for attributes

A survey is conducted to set the initial values in the university. The survey is done based on a questionnaire which was previously used by Salamzadeh et al. (2013a). Table 2 shows the results of this survey. 168 questionnaires were completely answered in this survey. Respondents were university officials, professors, staff, and students of the university. The table also shows the reliability of the questionnaire based on the calculated Cronbach's Alpha (Total: 0.95).

Table 2: Initial values for attributes, and their reliability

\begin{tabular}{||l|l|l|l||}
\hline \hline Entity & Attribute & $\begin{array}{l}\text { Initial } \\
\text { value }\end{array}$ & $\begin{array}{l}\text { Cronbach's } \\
\text { Alpha }\end{array}$ \\
\hline Mission & Generating Entrepreneurs & 0.43 & 0.67 \\
\hline \multirow{5}{*}{ Resources } & Applied research & 0.57 & 0.91 \\
\cline { 2 - 4 } & Knowledge and technology transfer & 0.53 & 0.74 \\
\cline { 2 - 4 } & Contribution in socio-economic development & 0.47 & 0.75 \\
\cline { 2 - 4 } & Developing an entrepreneurial culture & 0.58 & 0.67 \\
\hline Capabilities & Hard resources & 0.48 & 0.83 \\
\cline { 2 - 5 } & Soft resources & 0.46 & 0.62 \\
\cline { 2 - 4 } & Status and localization & 0.53 & 0.91 \\
\cline { 2 - 4 } & Background & 0.45 & 0.77 \\
\cline { 2 - 4 } & Networks and partners & 0.55 & 0.72 \\
\cline { 2 - 4 } & Resource absorption and management & 0.45 & 0.78 \\
\hline Impeding factors & Political behavior and lobbying & 0.53 & 0.88 \\
\cline { 2 - 4 } & Resistance & 0.44 & 0.81 \\
\hline
\end{tabular}

According to Sargent (1998) the validity of the model is confirmed. Various techniques are used to do so, which are:

(i) Face validity: face validity of the model is reached by confirmation of the experts in previous studies (Farsi et al., 2012; Salamzadeh et al., 2013a);

(ii) Historical validity: "One way to ensure greater historical validity is to require that a model accounts for a historical sequence of discoveries, rather than isolated events" (Zytkow and Simon, 1986). The proposed model in this research is a result of a series of studies which reveals a historical sequence of findings (e.g. see, Guerrero and Urbano, 2010; Sooreh et al., 2011; Salamzadeh et al., 2011, 2013a,b, 2015; Farsi et al., 2012; Guerrero et al., 2014).

(iii) Accepted approach: RBV is used as a basic theory in the modeling phase as an accepted approach to study entrepreneurial universities (e.g. see, Guerrero and Urbano, 2010; Salamzadeh et al., 2013a,b, 2015);

(iv) Derived from empirical data: the model was proposed and tested in different contexts (e.g. see, Guerrero and Urbano, 2010; Salmzadeh et al., 2013a; Guerreo et al., 2014). The data gathered in this survey also confirm the validity of the model.

(v) Theoretical derivation: the bases of the proposed model are Farsi et al (2012), Guerrero and Urbano (2010), Sooreh et al (2011), Salamzadeh et al., (2013a), and Guerrero et al., (2014).

\section{Step 2. Building a cross impact matrix}

In this step, the cross impact matrix is defined. To do so, the effects of columns on rows of attributes used as the basis to measure the effect of each attribute in the matrix. A pairwise 
correlation matrix which is created after data collection determines each $\mathrm{a}_{\mathrm{ij}}$. Table 3 shows the logic of turning qualitative data into quantitative data in order to measure the impacts. Finally, the cross impact matrix for the attributes of the study is prepared based on the interviews, which is shown in Table 4. Semi-structured interviews [SI] and secondary sources of data [SS] were used to gather more data about the proposed matrix. Interviews were tape recorded and fully transcribed. Three of the interviewees were selected and the authors asked them to check the process and to jot down what they saw as the main points that emerged from their interviews in order to check the validity of the data (Burnard, 1991).

Table 3: Impact rates of attributes

\begin{tabular}{||l|l|l||}
\hline Representation of Impact & Value & Description \\
\hline++++ & 0.8 & Very strong positive effect \\
\hline+++ & 0.6 & Strong positive effect \\
\hline++ & 0.4 & Moderate positive effect \\
\hline+ & 0.2 & Mild positive effect \\
\hline 0 & 0 & Neutral \\
\hline- & -0.2 & Mild negative effect \\
\hline-- & -0.4 & Moderate negative effect \\
\hline--- & -0.6 & Strong negative effect \\
\hline---- & -0.8 & Very strong negative effect \\
\hline \hline
\end{tabular}

Table 4:Cross impact matrix

\begin{tabular}{|c|c|c|c|c|c|c|c|c|c|c|c|c|c|}
\hline & GE & $\mathbf{A R}$ & KTT & CSED & DEC & HR & SR & SL & B & NP & RAM & PBL & $\mathbf{R}$ \\
\hline GE & & +++ & +++ & +++ & ++++ & ++ & ++ & 0 & 0 & +++ & +++ & -- & - \\
\hline$\overline{\mathbf{A R}}$ & 0 & & +++ & ++ & 0 & ++ & ++ & ++ & ++ & + & + & 0 & - \\
\hline KTT & ++ & +++ & & +++ & + & ++ & ++ & ++ & + & ++ & ++ & 0 & - \\
\hline CSED & + & 0 & 0 & & ++ & + & + & ++ & + & ++ & + & 0 & - \\
\hline DEC & +++ & +++ & +++ & +++ & & ++ & ++ & +++ & + & +++ & ++++ & -- & --- \\
\hline HR & + & ++ & ++ & + & ++ & & ++ & ++ & + & ++ & ++ & 0 & 0 \\
\hline SR & + & +++ & ++ & ++ & ++ & ++ & & +++ & ++ & ++ & ++ & - & - \\
\hline SL & +++ & ++ & ++ & +++ & ++ & ++ & ++ & & ++ & +++ & +++ & 0 & - \\
\hline B & +++ & + & + & +++ & +++ & ++ & +++ & ++++ & & +++ & ++ & 0 & - \\
\hline NP & +++ & +++ & +++ & +++ & ++ & + & +++ & +++ & 0 & & ++++ & + & + \\
\hline RAM & +++ & +++ & +++ & ++ & ++++ & +++ & ++++ & +++ & + & +++ & & - & - \\
\hline PBL & - & - & - & -- & -- & - & -- & - & 0 & 0 & + & & - \\
\hline $\mathbf{R}$ & --- & -- & -- & -- & -- & -- & --- & - & 0 & - & - & -- & \\
\hline
\end{tabular}

Legend: Generating entrepreneurs (GE), Applied research (AR), Knowledge and technology transfer (KTT), Contribution in socio-economic development (CSED), Developing an entrepreneurial culture (DEC), Hard resources (HR), Soft resources (SR), Status and localization (SL), Background (B), Networks and partners (NP), Resource absorption and management (RAM), Political behavior and lobbying (PBL), Resistance (R). behavior

Step 3. Simulating the model for a number of $m$ iterations, and illustrating the system's

In this phase, the model is simulated for $m$ iterations, and the behavior of each attribute is tabulated. When an attribute approaches its upper or lower bound, its response to a given impact decreases to zero, and the simulation process will be stopped. The results of the simulation are illustrated, and future scenarios are shown. No policy variable is entered into the model and the system's behavior is shown as is. Thus, figure 3 shows the system's behavior before adding the policy variables. As mentioned earlier, in the next phase policy variables are entered into the model and the system behavior is changed (Table 5). 


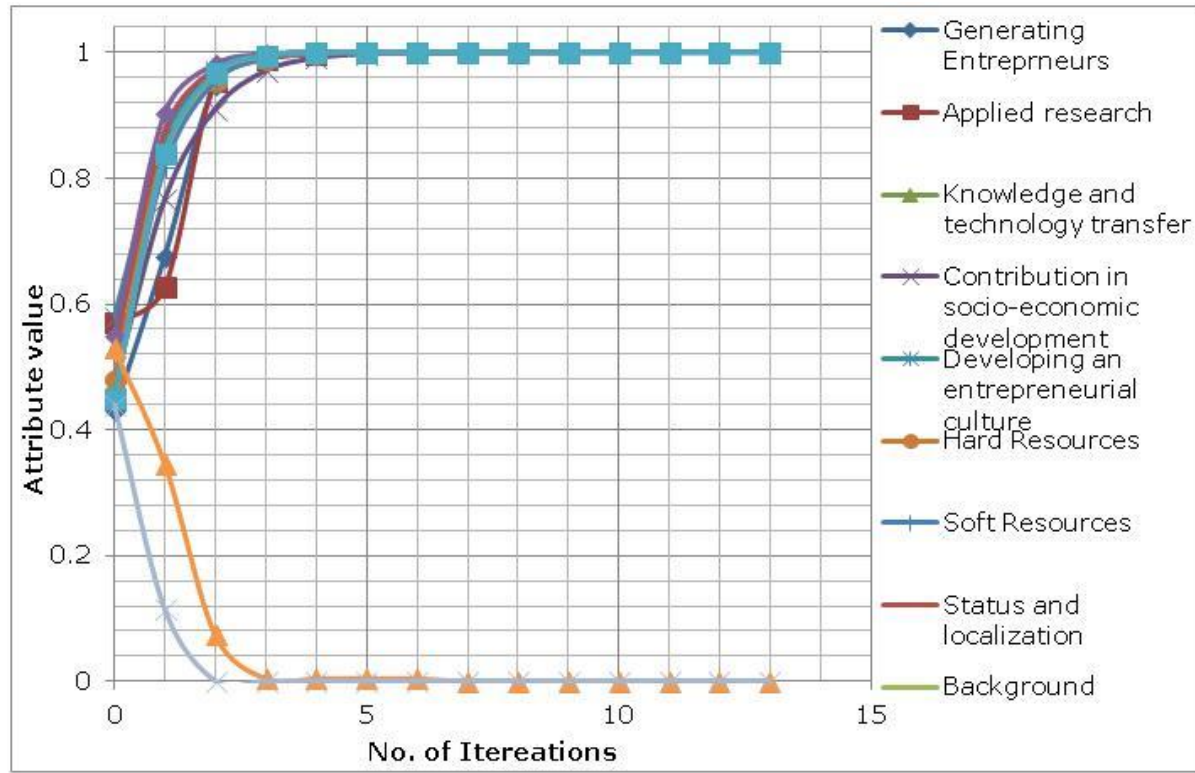

Figure 3: System's behavior before adding the policy variables

Step 4. Identification of policy variables and monitoring the changed system's behavior

This steps deals with monitoring the system's behavior after considering policy variables, to see if those policy variables improve or destroy the behavior. Thus, re-simulation is done. In this phase, two policy variables are considered:

(i) deficiencies of business environment rules and regulations $\left(\mathrm{P}_{1}\right)$, and

(ii) inertia in the university level system $\left(\mathrm{P}_{2}\right)$.

Table 6 shows the effect of each policy variable on each attribute.

Table 5: Effect of policy variables on each attribute

\begin{tabular}{|lll||}
\hline Attribute & P1 & P2 \\
\hline Generating Entrepreneurs & -- & -- \\
\hline Applied research & 0 & -- \\
\hline Knowledge and technology transfer & - & 0 \\
\hline Contribution in socio-economic development & -- & --- \\
\hline Developing an entrepreneurial culture & - & -- \\
\hline Hard resources & 0 & 0 \\
\hline Soft resources & - & - \\
\hline Status and localization & -- & 0 \\
\hline Background & -- & - \\
\hline Networks and partners & -- & --- \\
\hline Resource absorption and management & -- & -- \\
\hline Political behavior and lobbying & + & +++ \\
\hline Resistance & ++ & ++ \\
\hline \hline
\end{tabular}




\section{(i) Deficiencies of business environment rules and regulations $\left(P_{l}\right)$}

Business environment rules and regulations could affect the performance of universities and their academic entrepreneurship activities (Tanha et al., 2011). This policy variable is included into model to see what happens if the business environment works well. Prior research confirms that the failure of success of universities in being entrepreneurial and improving academic entrepreneurship activities depends on business environment (O'Shea et al., 2007; Etzkowitz and Zhou, 2007). Therefore, lack of enough appropriate rules and regulations is a critical factor to be included in the model (Rinne and Koivula, 2005). Moreover, business environment in Iran is so volatile, uncertain and complex (Talebi, 2007; Jacobson, 2008; Salamzadeh, 2015) that would impose limitations to the model (Arasti et al., 2012). Including this variable into the model, results show that the system will experience a lag after imposing the variables (see Table 7). This variable mainly affects capabilities and entrepreneurial mission. As it is shown in Table 6, different attributes of the mission and capabilities will be highly affected. This might be due to the great dependency of these two entities to rules and regulations; since universities are mainly supported and financed by the governments and this might be a critical issue.

(ii) Inertia in the university level system $\left(P_{2}\right)$

Some scholars believe that university level system is an important issue to be taken into account (Mehralizadeh, 2005; Salamzadeh et al., 2013a; Guerrero et al., 2014). Although this issue is important, inertia in this system would lead to failure of entrepreneurial activities in universities. Thus, this could directly affect the fulfillment of the Third Mission of universities (Jongbloed et al., 2008). Therefore, this policy variable is added to the model and re-simulation is done. Results show that inertia in the university level system could lead to a significant lag in reaching the optimum status (see Table 6). Inertia in the university level system highly affected soft resources, network and partners, and resource absorption. The inertia in the system is pretty great based on the figures and simulation results. Findings show that if the strategic directions are well-defined as well as strictly followed, and if sources of inertia are removed, academic entrepreneurship could be improved in universities. In sum, institutional inertia and barriers to the adoption of entrepreneurial spirit will worsen the situation. Moreover, the results show that impeding factors could directly affect the failure of system to be more entrepreneurial. Contribution in socio-economic development was the mostly affected attribute after considering policy variables.

Table 6: System's behavior before and after including policy variables

\begin{tabular}{||llll|}
\hline \multicolumn{1}{|c|}{ Attribute } & $\begin{array}{c}\text { Number of iterations } \\
\text { (before) }\end{array}$ & $\begin{array}{c}\text { Number of iterations } \\
\text { (after) }\end{array}$ & Difference \\
\hline Generating Entrepreneurs & 8 & 11 & 3 \\
\hline Applied research & 10 & 13 & 3 \\
\hline Knowledge and technology transfer & 9 & 10 & 1 \\
\hline $\begin{array}{l}\text { Contribution in socio-economic } \\
\text { development }\end{array}$ & 12 & 30 & 18 \\
\hline Developing an entrepreneurial culture & 7 & 10 & 3 \\
\hline Hard resources & 9 & 9 & 0 \\
\hline Soft resources & 8 & 11 & 3 \\
\hline Status and localization & 8 & 10 & 2 \\
\hline Background & 8 & 11 & 3 \\
\hline Networks and partners & 7 & 13 & 4 \\
\hline Resource absorption and management & 7 & 11 & 4 \\
\hline Political behavior and lobbying & 4 & 8 & 1 \\
\hline Resistance & 3 & 4 & \\
\hline
\end{tabular}




\section{CONCLUSION}

Academic entrepreneurship is realized through focusing on the Third Mission of universities which ensures the success of universities in becoming more entrepreneurial. However, this is not a simple problem to solve. Thus, in this paper, authors used Cross Impact Analysis (CIA) method as a system dynamics technique to monitor the system's behavior. In this research, the authors considered four entities and a series of attributes which constitute the model of study. The simulation was run to observe the system's behavior as is, and resimulation is done to enter two policy variables to see if the behavior changes. Results of the study revealed that the university is poorly engaged in entrepreneurial activities and the current status is not desirable. Also, the policy variables postponed the optimization of the model. These show that university officials should take serious actions to realize the Third Mission. Otherwise, the university would not be able to become a successful entrepreneurial university. There are some suggestions to improve the system which are as follows:

To revise the existing curriculum in order to include entrepreneurship in the courses. Since the level of generating entrepreneurs is almost low, i.e. 0.43, this could improve generating more entrepreneurs and thus help universities be more entrepreneurial.

To hold workshops, seminars, conferences, fairs and exhibitions to improve the knowledge of entrepreneurship. Although, knowledge and technology transfer seems to be good enough (0.53) to start this entrepreneurial journey, the present status is not sufficiently satisfactory, and it takes some years to make this improvement (see Table 6). Moreover, activating the technology transfer offices is another dilemma.

To take advantage of professors of practice. According to the facts and figures, applied research is improving in the country (0.57), but still there are some shortcomings. Collaborating with professors of practice is one of these issues which might improve the existing status, and cover the gap between universities and industries. Doing more entrepreneurial research in different faculties could also help universities to improve their entrepreneurial aspects.

To define a roadmap of entrepreneurship for at university and faculty levels. This could help universities in developing an entrepreneurial culture (0.58) in which entrepreneurship is an essential pillar to succeed. Moreover, devising support measures in order to motivate academics and students to act more entrepreneurially is another approach.

To make stronger connections with incubators, accelerators, science parks, and small business development centers. Such efforts could improve resource absorption and management (0.45) in universities. Opening new windows of opportunity for protecting intellectual property rights, and helping academics in commercializing their outputs is another solution.

As mentioned earlier, case study research forms the core of this research study. Thus the authors also noted several limitations that should be considered when using case study. The first limitation is the generalizability of the results. This should be considered in interpreting the findings and using the results in similar cases. However, a best practice is selected to be investigated, and policy variables were generally discussed in the literature. Thus, it would be up to the reader to determine whether the processes and steps described in this article could apply to their own circumstances. Second, the data were collected over a relatively short period of time. Then, it is recommended that further research explore the long-term effects of the model described above. However, the authors tried to use triangulation techniques to gather more reliable and relevant data in that limited period.

Future researchers might use other mathematical tools and techniques in data-mining such as RCMARS (Ozmen et al. 2010), GAM \& CQP (Alp et al. 2009), and CMARS (Weber et al. 2012), which would provide more fruitful insights than cross impact analysis. Moreover, this is the 
second system dynamics model proposed to study the entrepreneurial activities of universities or academic entrepreneurship (see, Salamzadeh et al., 2013a). Thus, future studies could make comparisons between the cases or conduct a multiple case study approach. A multiple case study might provide a more realistic view of the phenomenon in question. In addition to such research protocols, some scholars might study the interaction of different academic units to define a new model and solve the problem in a more creative way. Policy makers also could use such approaches for making new policies and measuring the effect of existing policies. Finally, our recommendation would be to try to further develop this study and put it into the broader theoretical context. This may be also the context of public policy/policies, stimulating the development of academic entrepreneurship, as implied by the model (See Figure 1).

\section{REFERENCES}

[1] Acworth, EB (2008). University-industry engagement: the formation of the knowledge integration community (KIC) model at the Cambridge-MIT Institute', Research Policy, 37(8), 1241-1254.

[2] Alp, Ö. S., Büyükbebeci, E., Çekiç, A. İ., Özkurt, F. Y., Taylan, P., \& Weber, G. W. (2011). CMARS and GAM \& CQP-Modern optimization methods applied to international credit default prediction. Journal of computational and applied mathematics, 235(16), 4639-4651.

[3] Andersson, S.,Berggren, E. (2016). Born global or local? Factors influencing the internationalization of university spin-offs - the case of Halmstad University. Journal of International Entrepreneurship, 14(3), 296-322.

[4] Arasti, Z., Zandi, F.,Talebi, K. (2012). Exploring the Effect of Individual Factors on Business Failure in Iranian New Established Small Businesses. International Business Research, 5(4), p2.

[5] Bruneel, J., D'Este, P.,Salter, A. (2010). Investigating the factors that diminish the barriers touniversity-industry Collaboration. Research Policy, 39(7), 858-868.

[6] Burnard, P. (1991). A method of analysing interview transcripts in qualitative research. Nurse education today, 11(6), 461-466.

[7] Chrisman, J.J., Hynes, T., Fraser, S. (1995). Faculty entrepreneurship and economic development: the case of the University of Calgary, Journal of Business Venturing, 10(4), 267281.

[8] Dana, L. P. (2001). The education and training of entrepreneurs in Asia. Education+ Training, 43(8/9), 405-416.

[9] De-liang, W. E. N. (2012). Practice and Reflections of Innovation and Entrepreneurship Education at China's Medical Universities. Northwest Medical Education, 2, 1-12.

[10] Dill, DD. (1995). University-industry entrepreneurship: The organization and management of American university technology transfer units", Higher Education, 29(4), 369-384.

[11] Etzkowitz, H. (2003). Innovation in Innovation: The Triple Helix of University-IndustryGovernment Relations. Social Science Information, 42(3), 293-337.

[12] Etzkowitz, H. (2011a). Special Introduction: Convergence of Science Parks, Centres and Clusters: From Creative Destruction to Creative Reconstruction in a Triple Helix Regime. International Journal of Technoentrepreneurship, 2(3/4), 210. doi:10.1504/IJTE.2011.043721

[13] Etzkowitz, H. (2011b). The triple helix: science, technology and the entrepreneurial spirit. Journal of Knowledge-based Innovation in China, 3(2), 76-90. doi:10.1108/17561411111138937

[14] Etzkowitz, H., Brisolla, S. N. (1999). Failure and success: the fate of industrial policy in Latin America and South East Asia. Research Policy, 28(4), 337-350. doi:10.1016/S00487333(98)00077-8 
[15] Etzkowitz, H., Mello,J. (2004). Rise of the Brazilian Triple Helix, International Journal ofTechnology Management and Sustainable Development, 2-3, 159-171. doi:10.1386/ijtm.2.3.159/1

[16] Etzkowitz, H., Leydesdorff, L. (2000). The dynamics of innovation: from National Systems and "Mode 2" to a Triple Helix of university-industry-government relations. Research Policy, 29(2), 109-123. doi:10.1016/S0048-7333(99)00055-4

[17] Etzkowitz, H., Zhou, C. (2007). Regional innovation initiator: the entrepreneurial university in various triple helix models. In Singapore Triple Helix VI Conference Theme Paper (pp. 1-25).

[18] Etzkowitz, H.,Zhou, C. (2008). Introduction to special issue $<$ BR $>$ Building the entrepreneurial university: a global perspective. Science and Public Policy, 35(9), 627-635. doi:10.3152/030234208X363178

[19] Etzkowitz, H., Webster, A., Gebhardt, C., Terra, B. R. C. (2000). The future of the university and the university of the future: evolution of ivory tower to entrepreneurial paradigm. Research Policy, 29(2), 313-330. doi:10.1016/S0048-7333(99)00069-4

[20] Farsi, J. Y., Modarresi, M., Motavaseli, M., Salamzadeh, A. (2014). Institutional Factors Affecting Academic Entrepreneurship: The Case of University of Tehran. Economic Analysis, 47(1-2), 139-159

[21] Farsi, J.Y., Imanipour, N.,Salamzadeh, A. (2012). Entrepreneurial University Conceptualization: Case of Developing Countries. Global Business and Management Research: An International Journal, 4(2), 193-204.

[22] Gartner, W. B. (1990). What are we talking about when we talk about entrepreneurship? Journal of Business Venturing, 5(1), 15-28. doi:10.1016/0883-9026(90)90023-M

[23] Gibb, A., Hannon, P. (2006). Towards the entrepreneurial university.International Journal of Entrepreneurship Education, 4(1), 73-110.

[24] Guerrero, M. Kirby, D.A.Urbano, D. (2006). A literature review on entrepreneurial university: an institutional approach. Working paper, Autonomous University of Barcelona. Barcelona, June.

[25] Guerrero, M., \& Urbano, D. (2010). The development of an entrepreneurial university. The Journal of Technology Transfer, 37(1), 43-74. doi:10.1007/s10961-010-9171-x

[26] Guerrero, M., Toledano, N., Urbano, D. (2011). Entrepreneurial universities and support mechanisms: a Spanish case study. International Journal of Entrepreneurship and Innovation Management, 13(2), 144. doi:10.1504/IJEIM.2011.038856

[27] Guerrero, M., Urbano, D., Salamzadeh, A. (2015). Entrepreneurial Transformation in the Middle East: Experiences from Tehran Universities. Technics Technologies Education Management, 10(4), 533-537.

[28] Guerrero, M., Urbano, D., Salamzadeh, A. (2014). Evolving Entrepreneurial Universities: Experiences and challenges in the Middle Eastern context. in Fayolle, A. \& Redford, D. T. (2014). Handbook of Research in Entrepreneurship Education: Entrepreneurial University Handbook Volume 4 Cambridge: Edward Elgar Publishing.

[29] Hayashi, A., Tokimatsu, K., Yamamoto, H.,Mori, S. (2006). Narrative scenario development based on cross-impact analysis for the evaluation of global-warming mitigation options. Applied Energy, 83(10), 1062-1075, DOI:10.1016/J.APENERGY.2005.11.002

[30] Howorth, C., Tempest, S., Coupland, C. (2005). Rethinking entrepreneurship methodology and definitions of the entrepreneur. Journal of Small Business and Enterprise Development, 12(1), 24-40. doi:10.1108/14626000510579626

[31] Jacobson, M. (2008). Sanctions against Iran: A promising struggle. Washington Quarterly, 31(3), 69-88.

[32] Jongbloed, B., Enders, J.,Salerno, C. (2008). Higher education and its communities: Interconnections, interdependencies and a research agenda. Higher Education, 56(3), 303-324.

[33] Kane, J. (2002). A Primer for a New Cross-Impact Language - KSIM. In: The Delphi Method: Techniques and Applications, Harold,A.L., and Murray, T. (eds.), Addison-Wesley. 
[34] Keast, D. A. (1995). Entrepreneurship in Universities: Definitions, Practices, and Implications. Higher Education Quarterly, 49(3), 248-266. doi:10.1111/j.1468-2273.1995.tb01679.x

[35] Kemp, M. W., Newnham, J. P.,Chapman, E. (2012). The biomedical doctorate in the contemporary university: education or training and why it matters. Higher Education, 63(5), 631-644.

[36] Khanna, S. (2016). A Journey from Surgeon to Surgeon Entrepreneur. The ClarionInternational Multidisciplinary Journal, 5(1), 141-146.

[37] Kirby, D. A., Guerrero, M., Urbano, D. (2011). Making universities more entrepreneurial: development of a model. Canadian Journal of Administrative Sciences, 28(3), 302-316.

[38] Kirby, D.A. (2006). Creating entrepreneurial universities in the UK: Applying entrepreneurship theory to practice. Journal of Technology Transfer, 31(5), 599-603.

[39] Klofsten, M. (2000). Training entrepreneurship at universities: a Swedish case. Journal of European Industrial Training, 24(6), 337-344. doi:10.1108/03090590010373325

[40] Laredo, P. (2007). Revisiting the third mission of universities: Toward a renewed categorization of university activities. Higher Education Policy. 20(4), 441-456.

[41] Loxley, A., Seery, A. (2012). The role of the professional doctorate in Ireland from the student perspective. Studies in Higher Education, 37(1), 3-17.

[42] Lu, L.,Etzkowitz, H. (2008). Strategic challenges for creating knowledge-based innovation in China: Transforming triple helix university-government-industry relations. Journal of Technology Management in China, 3(1), 5-11. doi:10.1108/17468770810851476

[43] Mautner, G. (2005). The entrepreneurial university: A discursive profile of a higher education buzzword. Critical discourse studies, 2(2), 95-120.

[44] Mehralizadeh, Y. (2005). New reforms in the management of the university: transition from centralized to decentralized (university-based management) in Iran. Higher Education Policy, $18(1), 67-82$.

[45] Mian, S. (2006). Can entrepreneurial university model help Pakistan leapfrog into the knowledge economy? Some reflections. Proceedings of the First International Conference on Assessing Quality in Higher Education, Lahore, December, 11-13.

[46] O'Shea, R. P., Allen, T. J., Morse, K. P., O'Gorman, C.,Roche, F. (2007). Delineating the anatomy of an entrepreneurial university: the Massachusetts Institute of Technology experience. $R \& d$ Management, 37(1), 1-16.

[47] Özmen, A., Weber, G. W., \& Batmaz, I. (2010). The new robust CMARS (RCMARS) method. preprint at IAM, METU, submitted to the ISI Proceedings of 24th MEC-EurOPT.

[48] Pedamallu, C. S., Ozdamar, L., Akar, H., Weber, G.-W.,Özsoy, A. (2011). Investigating academic performance of migrant students: A system dynamics perspective with an application to Turkey. International Journal of Production Economics. doi:10.1016/j.ijpe.2011.03.016

[49] Perkmann, M., Walsh, K., (2009). The two faces of collaboration: impacts ofuniversity\& industry relations on public research. Industrial and Cooperate Change, 18(6), 1033-1065.

[50] Rinne, R., Koivula, J. (2005). The Changing Place of the University and a Clash of Values The Entrepreneurial University in the European Knowledge Society A Review of the Literature. Higher Education Management and Policy, 17(3), 91.

[51] Salamzadeh, A. (2015). Innovation Accelerators: Emergence of Startup Companies in Iran. In 60th Annual ICSB World Conference June (pp. 6-9).

[52] Salamzadeh, A., Kawamorita Kesim, H. (2015). Startup Companies: Life Cycle and Challenges. In 4th International Conference on Employment, Education and Entrepreneurship (EEE), Belgrade, Serbia.

[53] Salamzadeh, A., Azimi., Kirby, D. A. (2013b). Social Entrepreneurship Education in Higher Education: Insights from Iran. International Journal of Entrepreneurship and Small Business. 20(1), 17-34. 
[54] Salamzadeh, A., Farsi, J. Y., Salamzadeh, Y. (2013a). Entrepreneurial universities in Iran: a system dynamics model. International Journal of Entrepreneurship and Small Business, 20(4), 420-445.

[55] Salamzadeh, A., Salamzadeh, Y., Daraei, M. (2011), Toward a Systematic Framework for an Entrepreneurial University: A Study in Iranian Context with an IPOO Model, Global Business and Management Research, 3(1), 30-37.

[56] Salamzadeh, A., Kawamorita Kesim, H. (2017). The enterprising communities and startup ecosystem in Iran. Journal of Enterprising Communities, 11(4), Forthcoming.

[57] Salamzadeh, A., Farsi, J.Y., Motevaseli, M., Radovic Markovic, M., Kawamorita, H. (2015). Institutional Factors Affecting the Transformation of Entrepreneurial Universities. International Journal of Business and Globalisation, 14(3), 271-291.

[58] Sargent, R. G. (1998). Verification and Validation of Simulation Models, Proceedings of 1998 Winter Simulation Conference, 121-130.

[59] Sooreh, L. K., Salamzadeh, A., Safarzadeh, H.,Salamzadeh, Y. (2011). Defining and Measuring Entrepreneurial Universities: A Study in Iranian Context Using Importance-Performance Analysis and TOPSIS Technique. Global Business and Management Research: An International Journal, 3(2), 182-199.

[60] Stone, D. A. (1997). The doctor as businessman: the changing politics of a cultural icon. Journal of Health Politics, Policy and Law, 22(2), 533-556.

[61] Svensson, P., Klofsten, M.,Etzkowitz, H. (2012). An Entrepreneurial University Strategy for Renewing a Declining Industrial City: The Norrköping Way. European Planning Studies, 20(4), 505-525. doi:10.1080/09654313.2012.665616

[62] Talebi, K. (2007). Entrepreneurship and SMEs Business Environment in Iran. Journal of Entrepreneurship Research, 1(1), 139-154.

[63] Tanha, D., Salamzadeh, A., Allahian, Z., Salamzadeh, Y. (2011). Commercialization of University Research and Innovations in Iran: Obstacles and Solutions. Journal of Knowledge Management, Economics and Information Technology, 1(7), 126-146.

[64] Thorp, H., Goldstein, B. (2013). Engines of innovation: The entrepreneurial university in the twenty-first century. UNC Press Books.

[65] Weber, G. W., Batmaz, İ., Köksal, G., Taylan, P., Yerlikaya-Özkurt, F. (2012). CMARS: A new contribution to nonparametric regression with multivariate adaptive regression splines supported by continuous optimization. Inverse Problems in Science and Engineering, 20(3), 371-400.

[66] Zytkow, J. M., Simon, H. A. (1986). A theory of historical discovery: The construction of componential models. Machine Learning, 1(1), 107-137.

\section{Article history:}

- Received 30 October 2016

- Accepted 19 April 2017 